\title{
Effect of landscape density in a residential area on thermal performance in a tropical climate.
}

\author{
Noorazlina Kamarulzaman ${ }^{1,2 a}$, Nor Amila Wan Abdullah Zawawi ${ }^{1}$ and Nurul Izma Mohammed ${ }^{1}$ \\ ${ }^{1}$ University of Technology MARA, Seri Iskandar Campus, 32610 Perak, Malaysia \\ ${ }^{2}$ University of Technology Petronas, 32610 Perak, Malaysia
}

\begin{abstract}
It is a well-documented that the urban air temperature is gradually growing in all cities due to the rapid development of buildings, roads and other infrastructure, human activities and also decreasing in vegetated areas. In a tropical climate, outdoor environment is clearly warmer than indoor environment due to higher air temperatures, particularly in dry seasons. Since the indoor environment is influenced by its surroundings, this situation indirectly contributes to the discomfort indoor environment in the building. Thus, it generates to the dependence on mechanical ventilation and increase the energy consumption in buildings. Many research studies have proof that plants not only beauty a city, but also improve the urban environmental condition by reducing the transferring of heat flux on buildings and increasing the reflection of radiation and shading. Therefore strategically placed vegetation around a building could decrease the energy consumption in buildings by reducing the adverse impact of some climate elements. Overall, this paper focuses on the results of a preliminary pilot study of two Semi-Detached houses with different landscape density in Seri Iskandar, Perak. Three climatic parameters, building configuration, and landscape design measured and analyze in this paper.
\end{abstract}

\section{Introduction}

Currently, the temperature of the most major cities around the world continues to grow due to the urban heat island phenomenon and the positive climatic change. Santamouris (2001) has mentioned that this phenomenon is the most documented for almost a century, and it related to higher urban temperatures compared to the adjacent suburban and rural areas [1]. In this modernization era, the urban area attracts the largest share of development investment, energy, and creativity. Today, $40 \%$ of the population of developing countries already lives in cities [2]. By 2020, it's expected that more than half of the population will live in the towns. The fast and mostly uncontrolled population growth create a pattern of rapid urbanization (Global Report on Human Settlements, 2001). Improved living standards and the increased population in developing countries contribute to a dramatic increase in energy consumption worldwide [4]. An increase in the urban population of $1 \%$ has been reported to increase energy use by $2.2 \%$ [5].

Globally, buildings handle approximately $40 \%$ of the total world annual energy consumption. Most of this energy are for the provision of lighting, heating, cooling, and air conditioning [6]. In Europe, buildings represent $40 \%$ of the overall energy consumption and $36 \%$ of the overall CO2 emissions (A.Ismail, Abdul Samad, Rahman, \& Yeok, 2012). According to Brown (2008), an annual energy consumption increase of $30 \%$ by the year 2020 was predicted by the International Energy Agency in 2008 [5]. A study of the tropical city of Singapore demonstrated that the use of air conditioning system has become a necessity to publics and contribute as the main factors to increase of energy consumption in building [8].

International Energy Agency (2009) stated that by 2030 average air temperature will rise by $2^{\circ} \mathrm{C}$ represent a critical limit [9]. Reflecting on this, various authors have agreed on the temperature level as a primary predictor of energy consumption for cooling inside and outside of the buildings. Therefore, the interactions between the indoor and outdoor thermal environments are necessary to be considered. Technically, there are many ways to improve the energy efficiency of the built environment. Improvements in building envelope technologies, such as wall, floor, and roof insulation, high-performance windows and doors, and air infiltration, have a priority role in producing a comfortable interior.

However, to improve energy efficiency using strategies mentioned above need extra financial cost and might be cannot be done by all. Therefore, the simplest and inexpensive method is by greening strategies in urban, especially in residential areas to improve the local air temperature. Good landscape arrangement can potentially decrease the amount of daylight entering the building and consequently, it's generating the comfortable temperatures for indoor and outdoor environments.

\footnotetext{
a Corresponding author: noorazlinakamarulzaman@yahoo.com
} 


\section{Current Situation}

In general, the issue of increasing of heat and energy consumption in a building is due to the increasing of outdoor temperature, and it relates to environmental problems such as global warming and heat island effects as discussed before. Memon, R. A et al.,(2008) stated that there are three reasons of Urban Heat Island which such as i) Anthropogenic heat released from vehicles, power plants, air conditioners and other heat from electrical appliances, ii) Enormous amounts of solar radiation due to less vegetation from rapid urbanization. iii) High unevenness structure is another problem of urban areas, which decreases the convective heat removal [10].

Ismail, A (2008) has mentioned that when the outdoor air temperature increases, the building will experience indoor discomfort conditions. The process of heat transfer through building fenestration such as windows and absorbed through the building envelope (walls and roofs) is the primary source of heat flow into buildings. Therefore, McPherson, Herrington et al. (1988) stated that landscaping can have a predominantly direct effect on local climate and linked to building thermal performance and one of the simplest strategies to reduce solar heat gain [12].

Strategically placed vegetation around a building has recognized as a one of cooling method. It decreases the amount of solar entering the building envelope through shading, moderating temperatures, evapotranspiration processes, and by controlling the wind direction to keep the building cool. With appropriate amount, species, and placement of vegetation can slow heat build-up on a hot summer day [5]. Expert researcher in landscaping also agrees that plant (trees, shrubs and grasses) can give significant effect to the local environment directly. By producing shading surfaces and channeling the wind, and by evapotranspiration of water (Akbari, H., Davis, S., Dorsano, S., Huang, J., \& Winnet, 1992; DOE, 1993; Misni, 2013). Shading is the most cost-effective way to diminish solar heat gain. Vegetation planted nearby the house will decrease the surrounding air temperatures and provide the best evaporative cooling. [15].

However, the effect of the surrounding landscaping on the thermal and energy performance of tropical domestic building has not been widely recognized or quantified. Therefore, the research aims to achieve three objectives i) To examine the potential of surrounding landscape to reduce the thermal performance of residential housing in a hot-humid tropical environment. ii) To measure the energy reduce rate through strategic landscaping around a residential building and iii) To proposed a model using Artificial Neutral Network to predict indoor thermal and energy consumption.

\section{$3 \quad$ Research Methodology}

As mentioned above, the microclimatic conditions are affected by adjacent buildings as well as by vegetation. For the aims of the preliminary study, the research methods only focusing on fieldwork measurement and its divided into three parts: 1) house with surrounding landscape selection, 2) survey and observation, and 3) fieldwork analysis for weather data and landscape elements. The aims of house selection were to identify and choose similar building design, constructions and site locations that were sufficiently different in their density of landscape structures and design.

The fieldwork measurement was to examine and compare the results of microclimate data between two houses that would directly influence the indoor thermal performance of the house. According to Akbari and Taha (1992), climatic factors that affect outdoor thermal comfort are (i) surface and air temperature; (ii) relative humidity; (iii) solar radiation; and (iv) wind velocity. Therefore, the interaction of these climate elements and its relation to local climate should be fully understood to define the appropriate approach to improving the urban thermal environment [16].

Technically, the primary instrument used for the fieldwork measurements included; (i)Two sets of portable weather station devices, model DeltaLog10 version 0.1.5.29, multi data logger and sensors to measure climatic parameters. (ii)One set of a compass and measuring tapes to identify the sun orientation and measure the house configurations. (iii)A set of layout plans to draw and record the house arrangements and landscape plans on site.

\section{$4 \quad$ Pilot Study}

The reference sites used in this research located in the residential area of Perak Tengah District. Two SemiDetached Houses located at Taman Iskandar Perdana, Seri Iskandar Perak, Malaysia $\left(4^{\circ} \mathrm{N}\right.$ latitude and $100^{\circ} \mathrm{E}$ Longitude) were chosen as a case study building. The houses situated in the same areas and route but separated by two houses in between as shown in Figure 1. The residential area consists of 52 single storey SemiDetached houses. For the purpose of the pilot study, only two houses with a similar conventional tropical design of architecture were chosen as a case study. The selection of building for the pilot test is due to the similarity of several criteria such as i) Ages of buildings. ii) Size of green area iii) Standard of construction, iv) Similar location but different in their landscape density, size, and orientation.

In this research, the study house was labeled as densely landscape house (House A) and sparsely landscape house (House B) according to the numbers of tree either single or group species, canopy size, and their height.

The house configuration was similar where both is east-west oriented and were constructed using similar building materials and construction. Both Semi-D houses had a similar size of a built-up area approximately $90.8 \mathrm{~m}^{2}$ or $7543 \mathrm{~mm} \times 12049 \mathrm{~mm}$ consists of a living room, dining, kitchen, three bedrooms with two bathrooms and one store room (refer Figure 2 for the overall view of the study houses). The primary structure was a reinforced concrete pad foundation; all had brick walls and a pitched aluminum- framed roof covered by the similar colour of concrete tiles. Ceiling heights for the two houses were 
around $3 \mathrm{~m}$ height and finished with fibrous, cement plaster, and asbestos free fiber cement ceiling sheets. All of the building openings constructed using glass with metal window frames for all casement windows and the sliding doors.

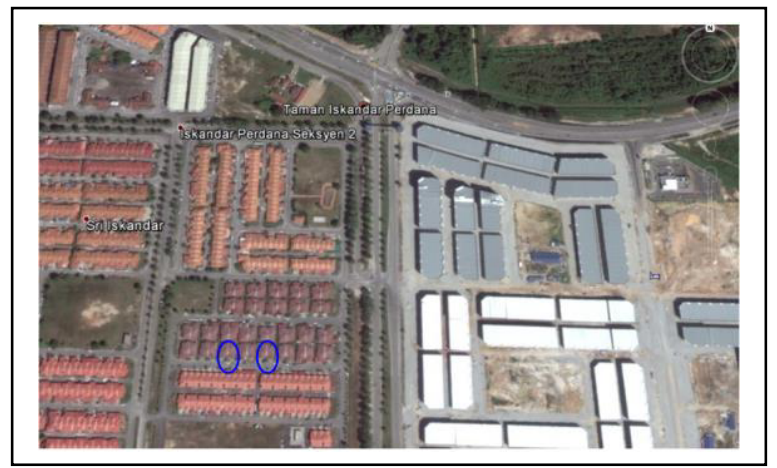

Figure 1: The blue circle shows the location of the study houses. (Source: Google Earth, 2015)

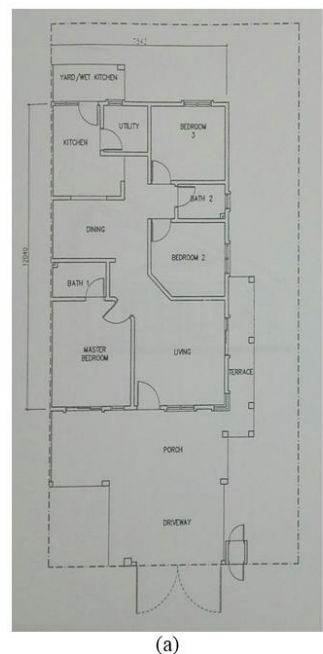

(a)

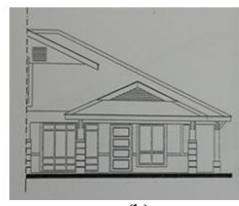

(b)

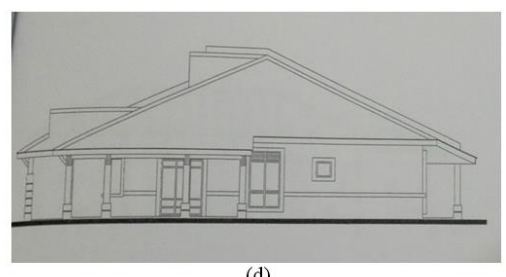

(d)

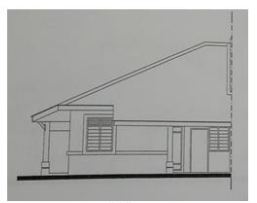

(c)
Figure 2: Figure (a), (b), (c) \& (d) shows floor plan, front, rear and side elevation of the study houses.

\section{$5 \quad$ Local Weather Record}

The weather recording was carried out in one day during daytime from 10.30 to 16.30 hours according to owner's permission and availability of the instrument. For the House B, data were collected on 20 August 2015 while for the House A is on 26 August 2015. Weather on these two days was very similar, where there was the sunshine for the whole day even though the data collection gaps are six days. This study measured meteorological parameters such as air temperature, humidity and wind velocity at 10 -minute intervals time using portable weather station devices. Data recording for this instrument was set automatically at the same time and placed at indoor and outdoor of the house approximately $1 \mathrm{~m}$ from the ground. The similar climatic parameters and time were recorded to compare the results and to ensure all data was accurate. Only one measurement point (MP) for indoors were recorded which is at the living room due to the constraint of access (marked as MP1). Meanwhile, three measurement points (MP2, MP3 \& MP4) for the outdoor climate were taken around these sites as shown in Figure 3. The distance of each measurement point is approximately $3 \mathrm{~m}$ from the building envelope. The climatic data recorded were not influenced by shadows or reflected solar radiation.

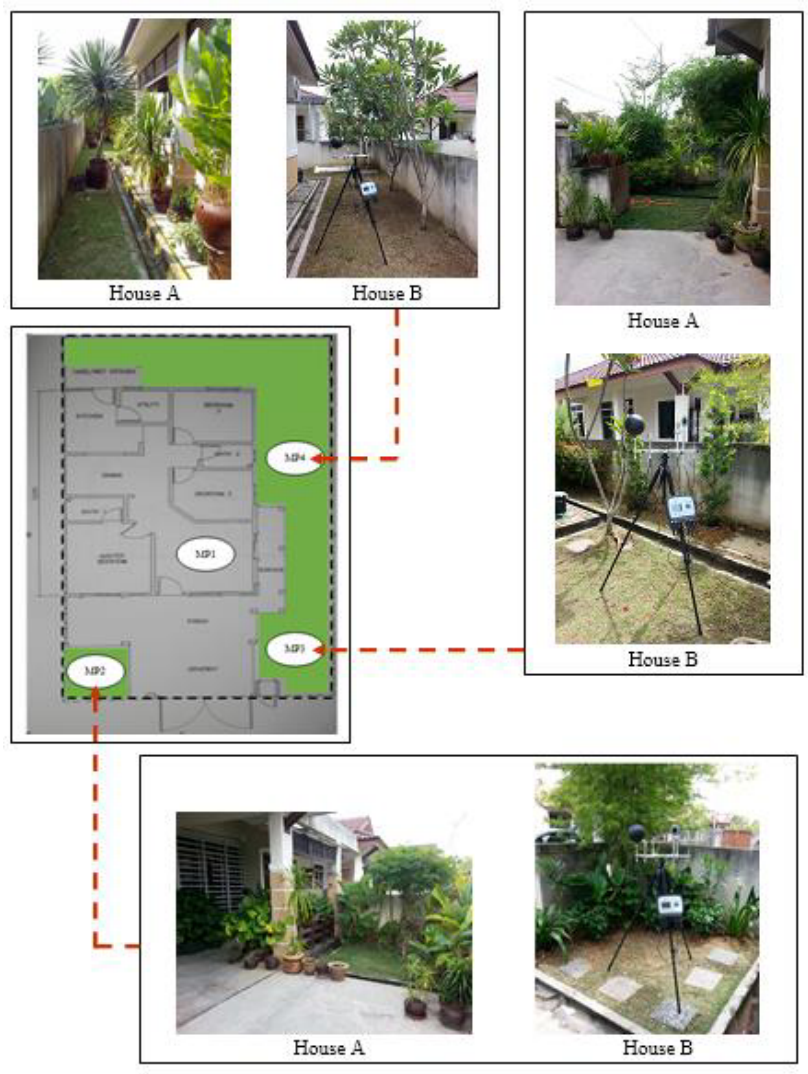

Figure 3: Plan is showing the location of measurement points for House A \& B.

\section{$6 \quad$ Pilot test results}

The fieldwork analysis was intended to identify the climatic parameters and landscape design around the two houses that have a significant effect on their local air temperature. The climate parameters measured in this research include air temperature, wind velocity, and relative humidity.

\subsection{Analyze Of Landscape}

The landscape surrounding of the two houses used a combination of trees, shrubs, ground cover and turf. The study of all landscape elements was done by observation and interviewed directly to the owner of the houses. Landscape elements for each building were drawn not to scale in layout plan as shown in Figure 4, and the photo of the landscape was captured to make a comparison. Both of the study house had a medium sized area for landscaping and situated on the left and right side of the building. A small area of landscape garden in rectangular 
shape approximately $2.5 \mathrm{~m} \times 2.5 \mathrm{~m}$ located at the front side between the Semi-Detached houses. Meanwhile, the other side of the landscape area is wider approximately $3 \mathrm{~m}$ width $\times 21 \mathrm{~m}$ length measured from the front side to the backyard. The owners personally inspired the tropical landscape design around the gardens. Each house had been planted with tropical plants for many reasons such as for beautiful view, edible, to create shade and to yield a lovely, comfortable and healthy environment. Both landscape houses planted with almost similar species of tree such as Calathea lutea, Crinum asiaticum, Bambusa $s p$. and all landscape garden covered with turf (refer Table 1\&2). They also used different amounts of trees and shrubs, species, and configurations of the plant. Edible plants planted in the backyard.

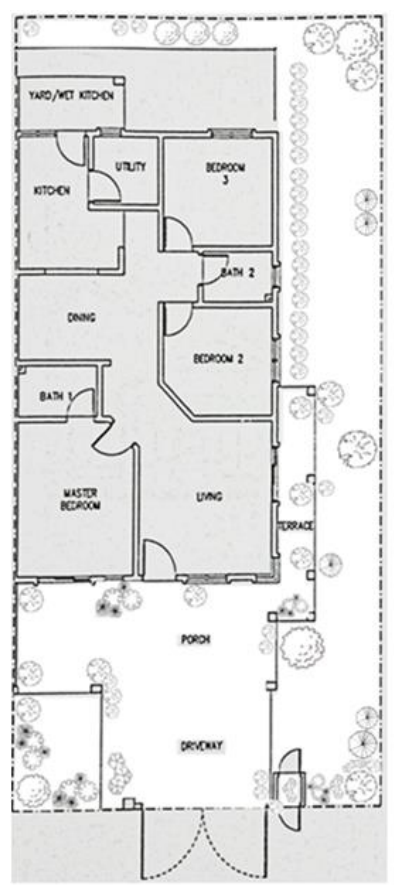

(a)

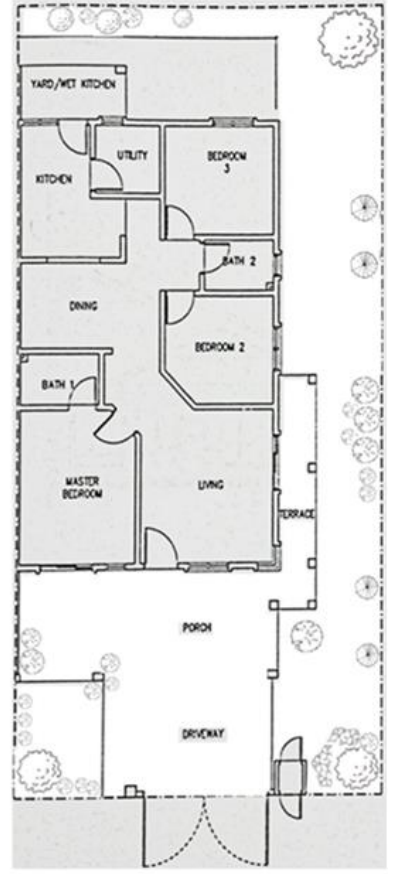

(b)
Figure 4: The arrangments of trees and shrubs around (a) Densely Landscape \& (b) Sparsely Landscape House

Table 1: List of trees, shrubs and ground cover at Densely Landscape House (House A)

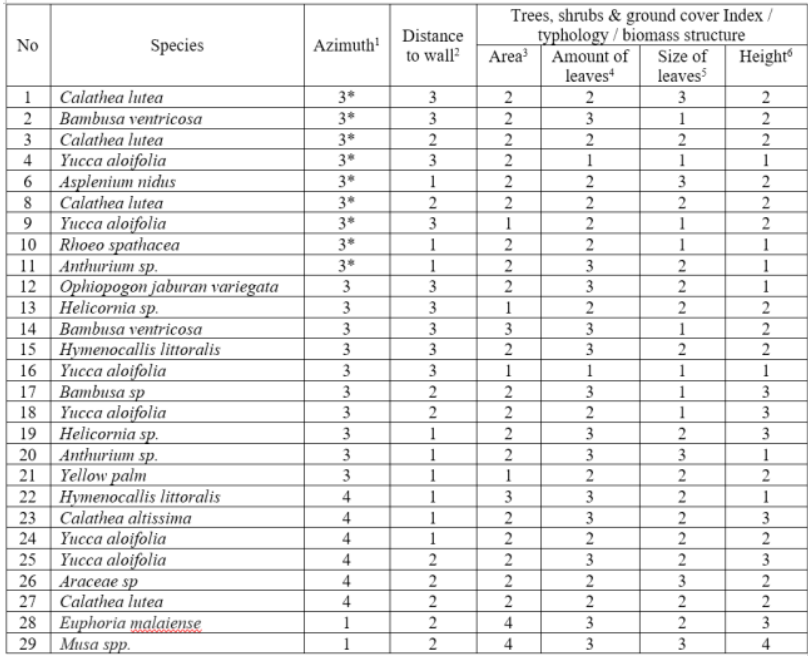

Table 2: List of trees, shrubs and ground cover at Sparsely Landscape House (House B)

\begin{tabular}{|c|c|c|c|c|c|c|c|}
\hline \multirow{2}{*}{ No } & \multirow{2}{*}{ Species } & \multirow{2}{*}{ Azimuth ${ }^{1}$} & \multirow{2}{*}{$\begin{array}{l}\text { Distance } \\
\text { to wall }\end{array}$} & \multicolumn{4}{|c|}{$\begin{array}{l}\text { Trees, shrubs \& ground cover Index / } \\
\text { typhology / biomass structure }\end{array}$} \\
\hline & & & & Area $^{3}$ & $\begin{array}{l}\text { Amount of } \\
\text { leaves }\end{array}$ & $\begin{array}{l}\text { Size of } \\
\text { leaves }^{5}\end{array}$ & Height $^{6}$ \\
\hline 1 & Bambusa ventricosa & $3^{*}$ & 3 & 2 & 3 & 1 & 4 \\
\hline 2 & Ixora javanica & $3^{*}$ & 3 & 2 & 2 & 1 & 1 \\
\hline 3 & Costus Woodsonii & $3^{*}$ & 3 & 2 & 2 & 1 & 1 \\
\hline 4 & Plumeria rubra & $3^{*}$ & 2 & 2 & 1 & 2 & 4 \\
\hline 5 & Bambusa ventricosa & 3 & 3 & 2 & 3 & 1 & 4 \\
\hline 6 & Hymenocallis littoralis & 3 & 3 & 1 & 3 & 2 & 1 \\
\hline 7 & Costus Woodsonii & 3 & 3 & 3 & 3 & 1 & 1 \\
\hline 8 & Calathea altissima & 3 & 3 & 3 & 3 & 2 & 2 \\
\hline 9 & Plumeria rubra & 3 & 2 & 1 & 1 & 2 & 1 \\
\hline 10 & Ixora javanica & 3 & 2 & 1 & 1 & 1 & 1 \\
\hline 11 & Costus Woodsonii & 3 & 2 & 1 & 1 & 1 & 1 \\
\hline 12 & Podocarpus & 2 & 2 & 1 & 2 & 1 & \\
\hline 13 & Podocarpus & 2 & 2 & 1 & 2 & 1 & 2 \\
\hline 14 & Ixora javanica & 2 & 2 & 2 & 3 & 1 & 2 \\
\hline 15 & Calathea lutea & 2 & 2 & 4 & 3 & 3 & 3 \\
\hline 16 & Plumeria rubra & 2 & 3 & 4 & 3 & 2 & 4 \\
\hline 17 & Mangifera indica Limn. & 1 & 3 & 5 & 3 & 2 & 4 \\
\hline 18 & Musa spp. & 1 & 2 & 3 & 3 & 3 & 4 \\
\hline 19 & Pandanus amarvilifoliou & 1 & 2 & 1 & & 1 & 1 \\
\hline
\end{tabular}

$1=$ North(right), $1^{*}=$ North(left), $2=$ East, $3=$ South(right), $3^{*}=$ South(left), $4=$ West

$1=$ proximity to walls, $2=$ below $3 \mathrm{~m}, 3=3-6 \mathrm{~m}$

$1=$ below $1 \mathrm{~m}^{2}, 2=1-4 \mathrm{~m}^{2}, 3=5-9 \mathrm{~m}^{2}, 4=10-14 \mathrm{~m}^{2}, 5=15-19 \mathrm{~m}^{2}$

$1=$ rare, $2=$ medium, $3=$ dense

1= small, $2-$ medium, $3=$ large

\subsection{Analyze of Climatic Parameters}

\subsubsection{Air Temperature}

From the data recorded, the air temperatures inside and outside of the densely landscaped house (House A) were lower than those in the sparsely landscaped house (House $\mathrm{B})$. The average outdoor temperature for House A and B is $32.5^{\circ} \mathrm{C}$ and $33.2^{\circ} \mathrm{C}$ respectively. Meanwhile, the average indoor temperature level shows a small differences rate at $0.1^{\circ} \mathrm{C}$. At 10.30 hours the indoor temperature in the House A was $30.1^{\circ} \mathrm{C}$ while the House B was $30.3^{\circ} \mathrm{C}$ as shown in Figure 5. The different landscaping amount and species resulted in only minor differences in this temperature level. Both houses reached their lowest indoor temperatures at 11.00 hours; $30.4^{\circ} \mathrm{C}$ at the House B and $29.7^{\circ} \mathrm{C}$ at the House A. The outdoor temperature for House $\mathrm{B}$ continues fluctuated until reaching the highest point of $36.2^{\circ} \mathrm{C}$ at 14.30 hours. The same pattern occurred at the House A, which reached its highest outdoor temperature of approximately $34.2^{\circ} \mathrm{C}$ at 15.30 hours. Overall, the outdoor temperature of the House A was as much as $3.8^{\circ} \mathrm{C}$ lower than the House B during the peak time of the day. In contrast, the indoor 
temperature at the House A and House B had a similar pattern and reading at all times. The apparent difference in temperature readings for the outdoor not much influence the ambient indoor temperatures might be due to activity in the house during the data recorded. Both houses uses natural ventilation during the day.



Figure 5: Indoor and outdoor air temperature results for House A and House B.

\subsubsection{Wind velocity}

Figure 6 shows the humidity pattern in $\mathrm{m}$ per second $(\mathrm{m} / \mathrm{s})$ at $1.5 \mathrm{~m}$ heights in two study houses. Outdoor wind velocity around both houses gradually rose in the morning, starting at 10.30 hours; $0.04 \mathrm{~m} / \mathrm{s}$ at the House A and $0.21 \mathrm{~m} / \mathrm{s}$ at House $\mathrm{B}$ until they reached the highest point at $0.93 \mathrm{~m} / \mathrm{s}$ and $0.56 \mathrm{~m} / \mathrm{s}$ respectively at 13.30 hours. Overall, an average data of wind velocity demonstrates that House B reached a higher rate for indoor and outdoor compared to House A. Less in cross ventilation due to enclosed space (windows and door closed) causes in decreasing of indoor wind velocity in both houses. The outdoor wind velocity then continues in the fluctuating pattern at throughout the day for both houses.

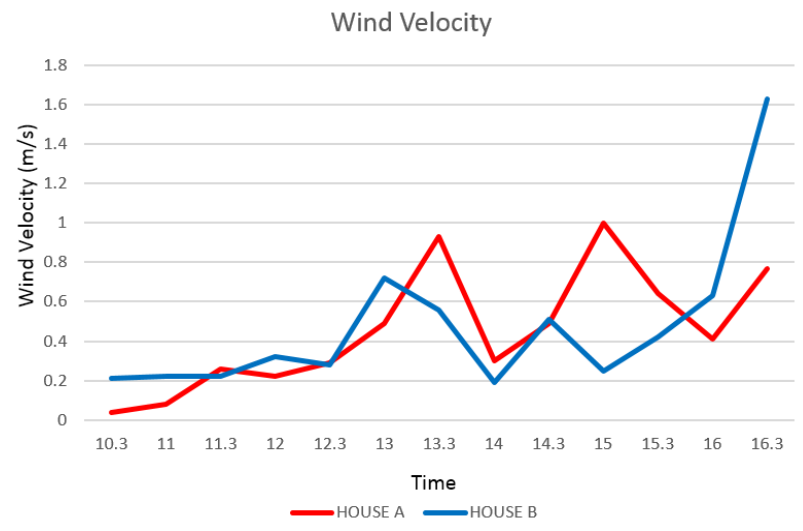

Figure 6: Wind velocity for the House A and House B.

\subsubsection{Relative Humidity}

During the morning, the ambient relative humidity (RH) readings at the House $\mathrm{A}$ is higher around $6.8 \%$ difference at 10.30 hours until the RH pattern slowly fell to the lowers point at $39.4 \%$ at 15.00 hours. In the middle of the day, the relative humidity levels of the House B were dramatically dropped around $21.7 \%$ starting at 12.30 hours to 14.30 hours. The graph also shows a big difference of $\mathrm{RH}$ between two houses at 14.30 hours around $19.4 \%$ (shown in Figure 7). However, all two house have a slightly similar in declining pattern in relative humidity.

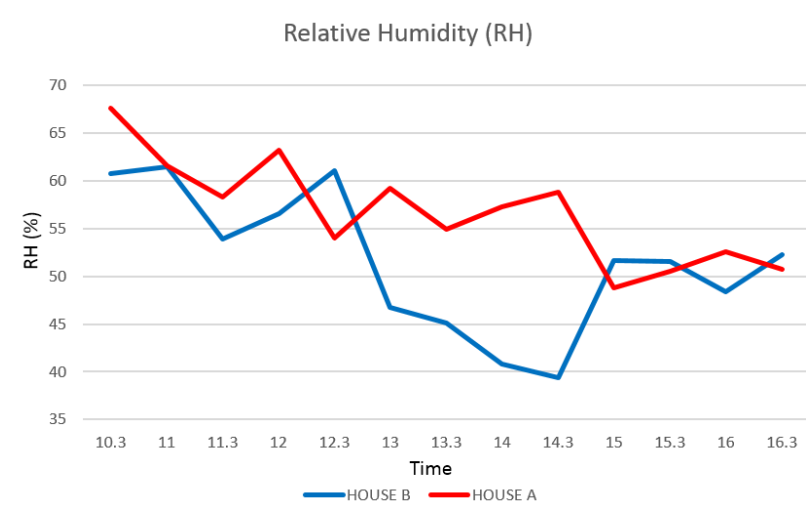

Figure 7: Relative Humidity for the House A and House B

\section{Conclusion}

This study presents quantitative finding regarding the cooling effect by altering the outdoor temperature in around two Semi-Detached houses with two landscaping strategies in a low density of residential zone in the tropical region. Study of the temperatures, relative humidity and wind velocity of the two houses of the outdoor and indoor facades revealed a quite interesting aspect of the passive cooling potential of landscaping.

Overall, the pilot test results show that outdoor temperature of the House A was $3.8^{\circ} \mathrm{C}$ lower than the House B and the percentage of Relative Humidity for House A were much higher about $19.4 \%$ during the afternoon. Meanwhile, an average data of wind velocity shows that House B reached a higher rate for indoor and outdoor compared to House A.

Strategic arrangement and design, sufficient numbers, and sizes of vegetation can provide the most efficient means of reducing outdoor air temperature around a residential building. The combination of shade trees, shrubs, vines, and groundcovers was predicted found to be the most efficient landscape strategy. This preliminary study apparently demonstrates the best technique to create a favourable environment for appropriate choice of plants, quantity, species and arrangement of landscaping for a tropical residential landscape.

\section{References}

[1] M. Santamouris, Energy And Climate In The Urban Built Environment. James And James Science Publishers, London., 2001.

[2] J. E. Anderson, G. Wulfhorst, and W. Lang, "Energy analysis of the built environment-A 
review and outlook," Renew. Sustain. Energy Rev., vol. 44, pp. 149-158, 2015.

[3] 2001 Global report on Human Settlements, "Cities in The Globalizing World.," 2006.

[4] M. Castelli, L. Trujillo, L. Vanneschi, and A. Popovič, "Prediction of Energy Performance of Residential Buildings: aGenetic Programming Approach," Energy Build., 2015.

[5] A. Misni, "The Effects of Surrounding Vegetation, Building Construction and Human Factors on the Thermal Perfomance of Housing in a Tropical Environment," 2012.

[6] L. Yang, H. Yan, and J. C. Lam, "Thermal comfort and building energy consumption implications - A review," Appl. Energy, vol. 115, pp. 164-173, 2014.

[7] A. Ismail, M. H. Abdul Samad, A. M. A. Rahman, and F. S. Yeok, "Cooling Potentials and $\mathrm{CO} 2$ Uptake of Ipomoea Pes-caprae Installed on the Flat Roof of a Single Storey Residential Building in Malaysia," Procedia - Soc. Behav. Sci., vol. 35, no. December 2011, pp. 361-368, Jan. 2012.

[8] C. P. Tso, "The Impact of Urban Development on the Thermal Environment of Singapore.," Pap. Present. Rep. Tech. Conf. Trop. Urban Clim. Dhaka, 1994.

[9] O. T. S. Yeo, K. Saito, and I. Said, "Quantitative Study of Green Area for Climate Sensitive Terraced Housing Area Design in Malaysia," IOP Conf. Ser. Earth Environ. Sci., vol. 18, p. 012101, 2014.

[10] L. I. U. Memon, R. A., Leung, D. Y. C., \& Chunho, "A Review On The Generation, Determination And Mitigation Of Urban Heat Island.," pp. 20, 120-128., 2008.

[11] M. H. A. S. A. A. M. A. R. Asmat Ismail, "Using Green Roof Concept As A Passive Design Technology To Minimise The Impact Of Global Warming..," 2nd Int. Conf. Built Environ. Dev. Ctries. (ICBEDC 2008), 2008.

[12] E. G. McPherson, L. P. Herrington, and G. M. Heisler, "Impacts of vegetation on residential heating and cooling," Energy Build., vol. 12, no. 1, pp. 41-51, 1988.

[13] S. Akbari, H., Davis, S., Dorsano, S., Huang, J., \& Winnet, Cooling our communities, a guidebook on tree planting and light-coloured surfacing Washington. Lawrence Berkerly Laboratory, 1992.

[14] DOE, "Tomorrow's Energy Today for Cities and Countries: Cooling Our Cities U.S.," Dep. Energy, pp. 1-6., 1993.

[15] A. Misni, "Modifying the Outdoor Temperature around Single-Family Residences: The Influence of Landscaping," Procedia - Soc. Behav. Sci., vol. 105, pp. 664-673, 2013.

[16] S. K. S. O. Thani, N. H. N. Mohamad, and S. Idilfitri, "Modification of Urban Temperature in Hot-Humid Climate Through Landscape Design Approach: A Review," Procedia - Soc. Behav. Sci., vol. 68, pp. 439-450, 2012. 